\title{
Features of chromosomal abnormalities in spontaneous abortion cell culture failures detected by interphase FISH analysis
}

Igor N Lebedev ${ }^{1}$, Nadezhda V Ostroverkhova ${ }^{1}$, Tatyana V Nikitina ${ }^{1}$, Natalia N Sukhanova ${ }^{1}$ and Sergey A Nazarenko*,1

${ }^{1}$ Cytogenetics Laboratory, Institute of Medical Genetics, Tomsk Scientific Centre, Russian Academy of Medical Sciences, 634050 Tomsk, Russia

Cytogenetic analysis of reproductive wastage is an important stage in understanding the genetic background of early embryogenesis. The results of conventional cytogenetic studies of spontaneous abortions depend on tissue culturing and are associated with a significant cell culture failure rate. We performed interphase dual-colour FISH analysis to detect chromosomal abnormalities in noncultured cells from two different tissues-cytotrophoblast and extraembryonic mesoderm-of 60 first-trimester spontaneous abortions from which cells had failed to grow in culture. An original algorithm was proposed to optimize the interphase karyotype screening with a panel of centromere-specific DNA probes for all human chromosomes. The overall rate of numerical chromosomal abnormalities in these cells was $53 \%$. Both typical and rare forms of karyotype imbalance were found. The observation of six cases (19\%) of monosomy 7, 15, 21 and 22 in mosaic form, with a predominant normal cell line, was the most unexpected finding. Cell lines with monosomies 21 and 22 were found both in cytotrophoblast and mesoderm, while cells with monosomy 7 and 15 were confined to the cytotrophoblast. The tissue-specific compartmentalization of cell lines with autosomal monosomies provides evidence that the aneuploidy of different human chromosomes may arise during different stages of intrauterine development. The effect of aneuploidy on selection may differ, however, depending on the specific chromosome. The abortions also revealed a high frequency of intratissue chromosomal mosaicism (94\%), in comparison with that detected by conventional cytogenetic analysis $(29 \% ; P<0.001)$. Confined placental mosaicism was found in $25 \%$ of the embryos. The results of molecular cytogenetic analysis of these cell culture failures illustrate that the diversity and phenotypic effects of chromosomal abnormalities during the early stages of human development are underestimated.

European Journal of Human Genetics (2004) 12, 513-520. doi:10.1038/sj.ejhg.5201178

Published online 31 March 2004

Keywords: spontaneous abortions; cell culture failures; numerical chromosomal abnormalities; autosomal monosomy; interphase cytogenetics

*Correspondence: Dr SA Nazarenko, Cytogenetics Laboratory, Institute of Medical Genetics, Tomsk Scientific Centre, Russian Institute of Medical Sciences, 634050 Tomsk, Russia;Tel: + 7382251 3146;

Fax: 7382251 3744; E-mail: Isnaz@img.tsu.ru

Received 9 October 2002; revised 23 December 2003; accepted 3 February 2004
Introduction

The crucial role of chromosomal imbalance in abnormal early human development is well established. Approximately $50-60 \%$ of first-trimester spontaneous abortions have karyotype abnormalities: mainly numerical chromosomal changes, such as autosomal trisomy, monosomy 
$\mathrm{X}$ and polyploidy. This conclusion is based on the results of cytogenetic studies conducted in laboratories throughout the world. ${ }^{1-7}$ Results of conventional cytogenetic analysis of spontaneous abortions strongly depend on tissue culturing and are associated with a significant culture failure rate, which varies from 5 to $42 \%$ in different laboratories. ${ }^{2,3}$ The cytogenetic factors of cell death in vitro are not sufficiently investigated. It is possible to assume that tissue culture failure is a marker of particular genomic imbalances incompatible with normal cell proliferation. If this hypothesis is true, then the standard cytogenetic analysis of spontaneous abortions may underestimate the frequency and diversity of detected chromosomal abnormalities. Current molecular cytogenetic techniques, such as comparative genomic hybridization (CGH) and fluorescence in situ hybridization (FISH) on interphase nuclei, provide an excellent possibility for karyotype screening in noncultured cells. Interphase FISH has advantages over CGH because it allows the detection of all types of numerical abnormalities (aneuploidy and polyploidy), including mosaic forms. The aim of the present study was to investigate chromosomal abnormalities in spontaneous abortion cell culture failures by interphase FISH analysis of noncultured cells with low proliferative capacity.

\section{Material and methods} Tissue samples and controls

Extraembryonic tissues had been collected as part of a cytogenetic study of spontaneous abortions at the Cytogenetics Laboratory of the Institute of Medical Genetics, Tomsk, Russia. A total of 146 samples were received from women with echographically diagnosed missed abortions (111 samples) or blighted ovums (35 samples). Gestation ages varied from 5 to 12 weeks. The samples of 13 induced abortions, from healthy women of 6-12 weeks of normal pregnancy, were used to determine the cutoff level of spontaneous aneuploidy and polyploidy by interphase FISH in extraembryonic tissues. All patients gave informed consent for research.

After termination of the pregnancies, tissue samples were immediately delivered to the laboratory. Samples were released from maternal decidua and blood clots and were divided into two parts, which were used for cell culture or for the preparation of noncultured single-cell suspensions. Long-term cultures, preparation of metaphase chromosomes and G-banding were performed by standard protocols. ${ }^{1}$ Cells were cultivated in medium containing Ham F-12 (60\%), DMEM (30\%), fetal bovine serum (10\%), amino acids and vitamins (Sigma, USA). At least 15 metaphase spreads were analysed for each sample. The non-cultured single cell suspensions from spontaneous and induced abortions were prepared from cytotrophoblast and extraembryonic mesoderm. The former were prepared by disaggregation in $60 \%$ acetic acid of previously fixed chorion (methanol/acetic acid, 3:1). The extraembryonic mesoderm cells were obtained by digesting fresh fetal membranes with $125 \mathrm{U} / \mathrm{ml}$ collagenase type I (Sigma, USA) for $30-60 \mathrm{~min}$ at $37^{\circ} \mathrm{C}$. Cell suspensions were fixed and stored in 3:1 methanol/acetic acid at $-20^{\circ} \mathrm{C}$.

\section{Interphase FISH analysis}

Noncultured single cell suspensions from spontaneous abortions, from which cells had failed to grow in culture, were selected for dual-colour interphase FISH with centromere-specific DNA probes. The selection criteria were complete failure of a tissue explant to attach to the substratum, lack of cell proliferation in culture, or a statistically significant increase of average cell culture duration prior to a degeneration phase $(111.5 \pm$ 49.5 days, in comparison with normally proliferating cells, which reach log phase within $20.5 \pm 13.9$ days $(P<0.0001))$.

Interphase FISH analysis was performed by an original algorithm based on the frequencies of the autosomal trisomies in spontaneous abortions (Figure 1). It is well known that the rates of trisomies vary for different chromosomes. Thus, trisomy 16 is the prevalent aneuploidy in spontaneous abortions, ${ }^{8}$ trisomies $13-15,18,21$ and 22 are less frequent, and trisomies 1,5 and 19 are described in single instances. ${ }^{1,6,9}$ The most effective karyotype screening will involve priority analysis of chromosome copy numbers, according to the average frequency of the corresponding trisomies.

DNA probe labelling by nick-translation with biotin-16dUTP or digoxigenin-11-dUTP (Boehringer Mannheim) and dual-colour interphase FISH were performed according to standard protocols. ${ }^{10}$ The centromere-specific DNA probes for all human chromosomes were kindly donated by Prof M Rocchi (University of Bari, Italy). Additional centromere-specific DNA probes D22Z and D21S65 (Appligene and Oncor, USA) were used for the differentiation of $14 / 22$ and 13/21 chromosomes, respectively. About 500-1200 interphase nuclei were scored in each hybridization reaction. Differences between the observed frequencies of additional cell lines in mosaic karyotypes and the spontaneous mutation rate were estimated by the one-sided upper reference limits with the corresponding 95\% confidence intervals. ${ }^{11}$ At least 1000 interphase nuclei in every control sample tissue were analysed with dual-colour FISH technique to determine a cutoff level for each type of aneuploidy or polyploidy. Slides were analysed with a fluorescence microscope (Zeiss, Germany) equipped with a CCD-camera. Image analysis was performed by a 'PowerGene 7100 ' system and 'MacProbe, Version 3.2.1' software (PSI, USA). $\chi^{2}$ and Fisher's exact tests were used for statistical analysis. 


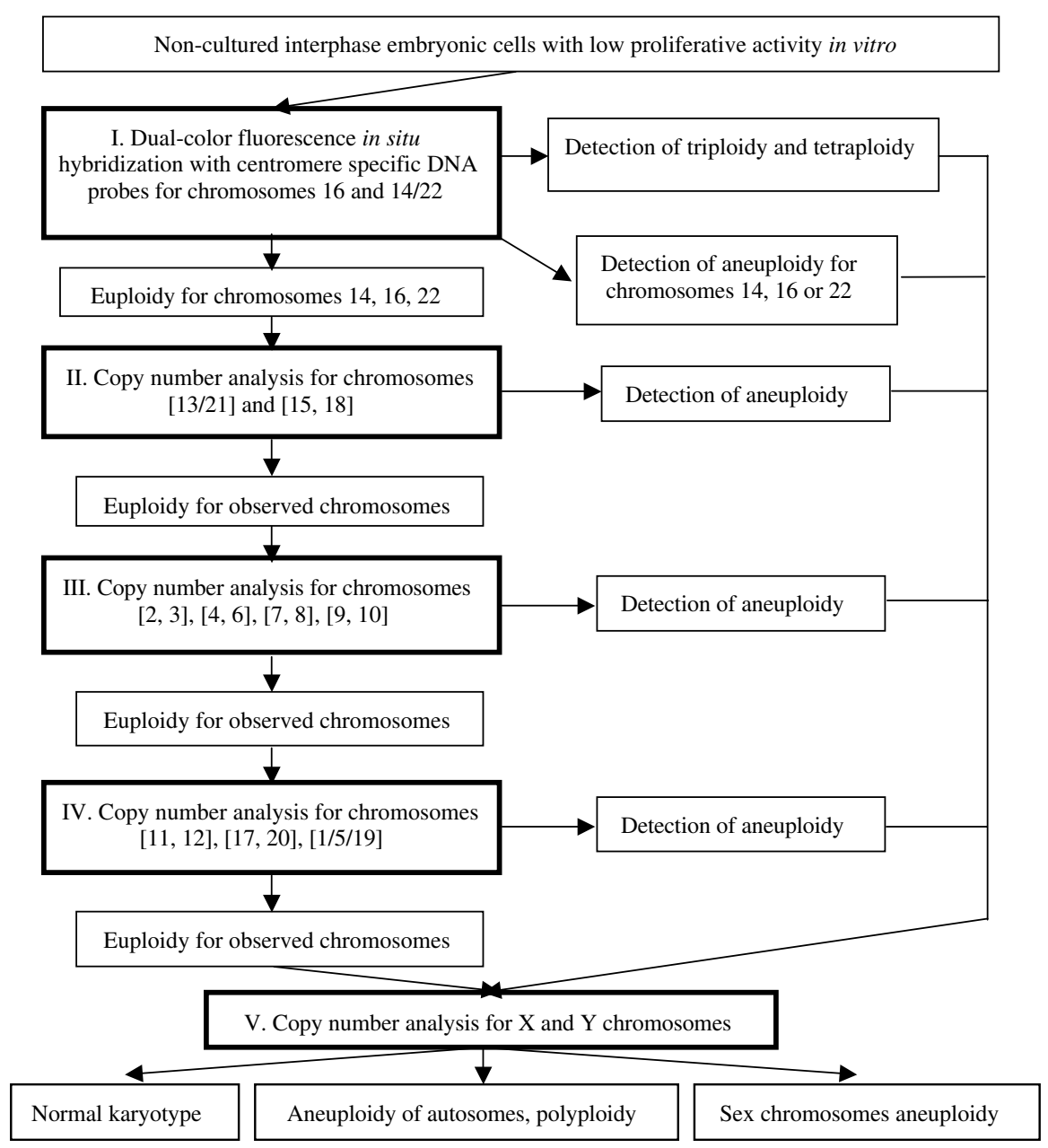

Figure 1 Algorithm of karyotype screening by interphase FISH analysis of non-cultured spontaneous abortions cells with low proliferative activity in vitro.

\section{Results}

A total of 60 spontaneous abortions, from which cells had failed to grow in vitro, were studied by dual-colour interphase FISH of noncultured cells of two different tissues - cytotrophoblast and extraembryonic mesoderm (Table 1). The overall rate of detected numerical chromosomal abnormalities was 53\%.

Trisomies of autosomes were the predominant chromosomal aberrations (50\%). The incidence of sex chromosomes aneuploidies was 13\%, followed by triploidy (9\%) and tetraploidy (9\%). All these types of numerical chromosomal abnormalities are typical for human spontaneous abortions. Surprisingly, six cases of monosomy were detected for chromosomes 7, 15, 21 and 22 in mosaic form with a predominant normal cell line (Table 2). The frequency of autosomal monosomies in samples with low proliferative capacity was $19 \%$. Cell lines with monosomies 21 and 22 were found both in cytotrophoblast and mesoderm, while cells with monosomies 7 and 15 were confined to the cytotrophoblast only. We found no statistical differences between maternal age of embryos with normal karyotype $(26.3 \pm 5.8)$ and abortions with autosomal monosomies $(25.5 \pm 6.3 ; P=0.76)$.

The results of interphase FISH analysis were compared with conventional cytogenetic data of 86 spontaneous abortions that had shown normal cell proliferation in the same culture conditions. Comparison of the frequencies and types of detected chromosomal abnormalities in both groups of spontaneous abortions are given in Table 3.

The interphase FISH analysis of noncultured cells with low proliferative activity also revealed a high frequency of intra-tissue chromosomal mosaicism. Among 32 spontaneous abortions with chromosomal abnormalities, 30 conceptions (94\%) had two or more cell lines with different chromosomal constitution. Confined placental mosaicism was found in seven embryos (25\%) (Table 1).

Different cell lines in placental tissues were unlikely to be due to maternal cell contamination, since $66.7 \%$ of the 
IN Lebedev et al

516

Table 1 Chromosomal abnormalities in noncultured cells with low proliferative activity in vitro, isolated from spontaneous abortions

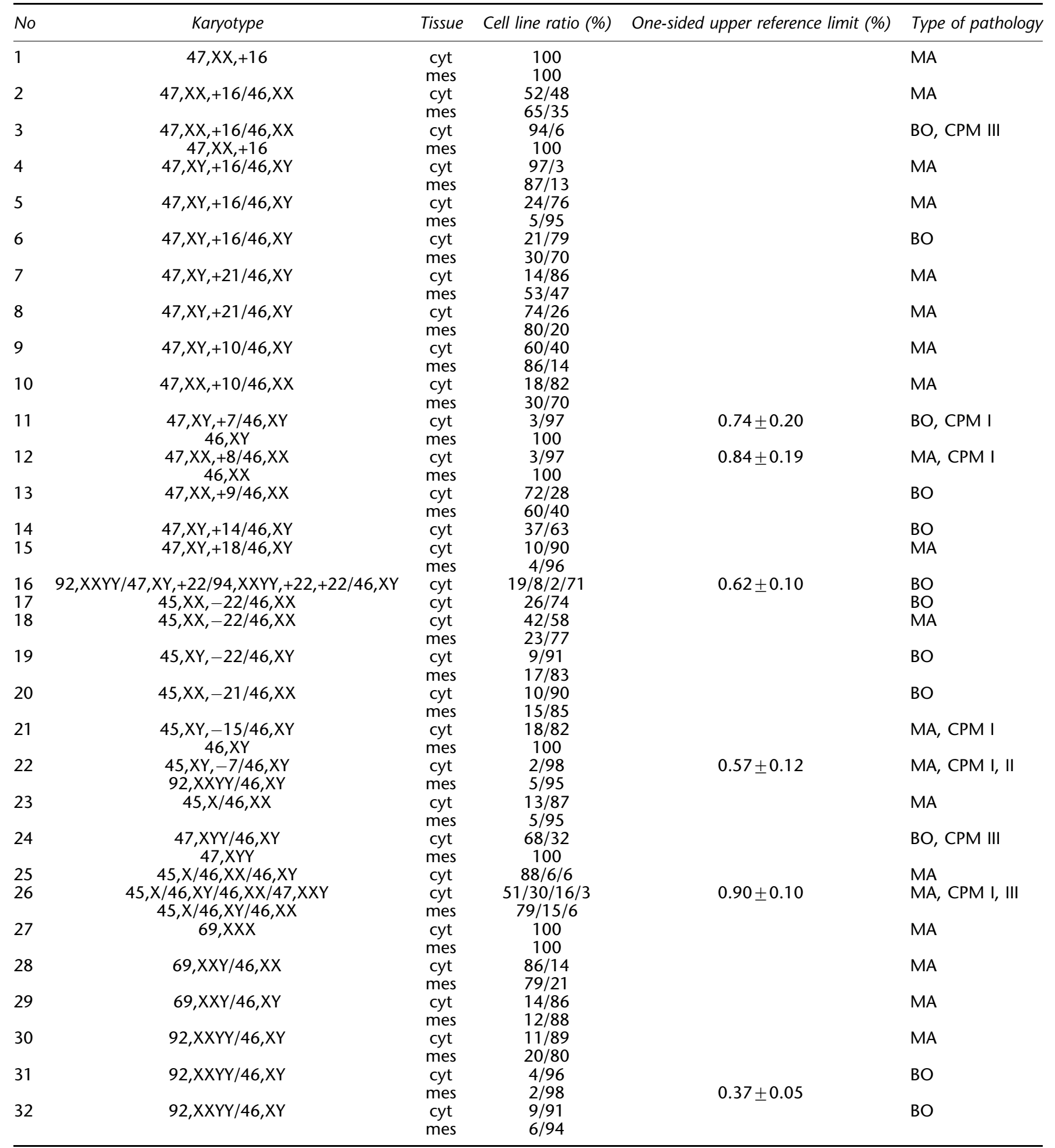

cyt = cytotrophoblast; mes = extraembryonic mesoderm; MA = missed abortion; BO = blighted ovum; CPM I, II, III = confined placental mosaicism, type I, II, III. ${ }^{24}$ 
Table 2 Distribution of cell lines in different placental tissues of first-trimester spontaneous abortions with autosomal monosomies

\begin{tabular}{|c|c|c|c|c|}
\hline No & Cytotrophoblast & Extraembryonic mesoderm & Tissue-specific differences (P) & Type of development disorder \\
\hline 1 & $45, X Y,-15 / 46, X Y(18 / 82)$ & $46, X Y$ & - & MA, 8 weeks \\
\hline 2 & $45, X Y,-7 / 46, X Y(2 / 98)$ & $92, X X Y Y / 46, X Y(5 / 95)$ & - & MA, 7 weeks \\
\hline 3 & $45, X X,-22 / 46, X X(42 / 58)$ & $45, X X,-22 / 46, X X(23 / 77)$ & $<10^{-5}$ & MA, 8.5 weeks \\
\hline 4 & $45, X X,-22 / 46, X X(26 / 74)$ & $N / A$ & - & BO, 5 weeks \\
\hline 5 & $45, X Y,-22 / 46, X Y(9 / 91)$ & $45, X Y,-22 / 46, X Y(17 / 83)$ & 0.01 & BO, 5 weeks \\
\hline 6 & $45, X X,-21 / 46, X X(10 / 90)$ & $45, X X,-21 / 46, X X(15 / 85)$ & 0.22 & BO, 8 weeks \\
\hline
\end{tabular}

The ratio of cell lines is given in parentheses; $\mathrm{MA}=$ missed abortion; $\mathrm{BO}=$ blighted ovum; $\mathrm{N} / \mathrm{A}=$ non available.

Table 3 Comparison of chromosomal abnormalities in 146 first-trimester spontaneous abortions with normal and low cell proliferative capacity

\begin{tabular}{|c|c|c|c|}
\hline Karyotype & $\begin{array}{c}\text { Cell culture failures (interphase } \\
\text { FISH analysis)(\%) }\end{array}$ & $\begin{array}{c}\text { Successful cell cultures } \\
\text { (conventional cytogenetic } \\
\text { analysis) (\%) }\end{array}$ & P-value \\
\hline Autosomal trisomy & $16(50)$ & $25(53)$ & 0.48 \\
\hline Autosomal monosomy & $6(19)$ & 0 & 0.003 \\
\hline Triploidy & $3(9)$ & $9(19)$ & 0.19 \\
\hline Tetraploidy & $3(9)$ & $8(17)$ & 0.27 \\
\hline $\begin{array}{l}\text { Total number of numerical chromosomal } \\
\text { aberration }\end{array}$ & $32(53)$ & $47(56)$ & 0.50 \\
\hline Structural chromosomal aberrations & - & 2 & \\
\hline Total & 60 & 86 & \\
\hline
\end{tabular}

Figures in parentheses apply to numerical chromosomal aberrations only.

mosaic embryos had XY chromosomal constitution, while the sex ratio for embryos with low cell proliferation and normal karyotype was 1.00 .

Mosaic karyotypes were also found in aborted material with normal cell proliferation using classical cytogenetic analysis. However, their frequency was significantly lower than in spontaneous abortions from which cells had failed to grow in culture $(P<0.001)$. Thus, only 14 of the 49 spontaneous abortions with chromosomal abnormalities (29\%) detected by metaphase analysis had mosaic karyotypes: 11 embryos had diploid/tetraploid mosaicism, two had disomy/trisomy mosaicism, and one had a diploid/ triploid karyotype. The sex ratio for embryos with normal cell proliferation and a normal karyotype was 0.68. No significant differences between the sex ratio in cultured and non-cultured cells with normal karyotype were observed (the $\chi^{2}=0.26, P=0.61$ ), therefore it was unlikely that there was maternal cell contamination in our material.

\section{Discussion}

The hypothesis that the proliferative capacity of cells is connected with chromosomal constitution has long been discussed. ${ }^{12-14}$ The results of the investigations presented here indicate that the majority of cells with chromosomal aberrations are able to support their own proliferation in vitro for a limited time. Recent data on amniotic cell culture failures show that the frequency of abnormal karyotypes is much greater in those pregnancies in which culture failure occurs, in comparison with those in which a cytogenetic result is obtained $(10-19 \%$ vs $1-4 \%) .{ }^{15-17}$ Current molecular cytogenetic techniques have a great potential for the analysis of chromosomal aberrations in spontaneous abortion cell culture failures, but only three papers devoted to this problem have been published. ${ }^{18-20}$ In these studies, chromosomal abnormalities were detected in $47-72 \%$ of the cases. However, all these investigations were performed using the CGH technique, which has limitations for the detection of low-level mosaicism and polyploidy.

For the first time, we have applied an interphase FISH approach to the study of cell culture failures in spontaneous abortions. This allows the detection of all types of numerical chromosomal abnormalities and provides a powerful tool for the screening of mosaicism. The laborious nature of the work can be greatly reduced by the proposed diagnostic algorithm, which provides the correct estimation of karyotype abnormalities, excluding structural aberrations and multiple aneuploidy. It is known that the structural aberration rate in human spontaneous abortions is lower than $5 \% .^{1-7}$ The double or triple trisomies are also rare events, accounting for $1.38 \%$ and 
$0.05 \%$ respectively, on average. ${ }^{21,22}$ Therefore the statistical power of the proposed algorithm tends to $95 \%$.

The overall incidence of numerical chromosomal abnormalities detected in noncultured cells of spontaneous abortions with low cell proliferation was 53\%. This figure is similar to the frequency of aberrations usually revealed by conventional cytogenetics in the first-trimester pregnancy loss $(50-65 \%) .{ }^{1-7}$ Further, we found no statistical difference between the overall rates of numerical chromosomal abnormalities in cells with low and normal proliferative capacity (Table 3 ).

Similar data were obtained in all three above-mentioned CGH-based studies ${ }^{18-20}$ (Table 4), although some of the investigators ${ }^{20}$ suggested that the contribution of chromosome aberrations to the first trimester pregnancy loss is nearly $70 \%$. On the other hand, differential effects of particular forms of chromosomal imbalance on cell proliferation are possible. Our data show that the spectrum and rate of some types of karyotype disorders differ in cells with varying proliferative capacity in vitro. Specifically, the frequency of mosaic autosomal monosomies in embryos with cell culture failures was $19 \%$.

Autosomal monosomy is a very rare finding among spontaneous abortions. Only a few cases are known of this type of aneuploidy in embryos. ${ }^{1,4,5}$ It is suggested that the overwhelming majority of such zygotes are eliminated before implantation. ${ }^{23}$ The observation of embryos with mosaic autosomal monosomies indicates that these conceptions have passed the early stages of postimplantation differentiation. We have evaluated a tissue-specific distribution of cell lines with autosomal monosomies in cytotrophoblast and extraembryonic mesoderm. These tissues differentiate from various extraembryonic and embryonic progenitors, hence the pattern of abnormal cell line distribution can specify the time and stage of intrauterine development at which chromosomal abnormalities arose. ${ }^{24}$ Our results indicate that cell lines with monosomy 7 and 15, which have not previously been described in spontaneous abortions, were confined to the cytotrophoblast only. Such type of cell line compartmentalization can arise due to mitotic nondisjunction in cytotrophoblast cells after differentiation of trophoblast and epiblast, that is, after the implantation stage. There- fore, the implanted blastocyst in these cases had a normal karyotype. On the contrary, the presence of abnormal cell lines with monosomies 21 and 22 both in cytotrophoblast and mesoderm showed that the blastocysts carried a monosomy and were compatible with normal implantation. This assumption is confirmed by the fact that monosomies 21 and 22 have been registered in samples of spontaneous abortions. ${ }^{1,4,5}$ Moreover, unique cases of newborns with monosomy 21 are described. ${ }^{25,26}$ Ginsburg et $a l^{27}$ has shown that hypohaploid oocyte frequency is associated with increasing maternal age. However, in our study we found no statistical differences between maternal age of embryos with normal karyotype and abortions with autosomal monosomies.

The underlying mechanisms of phenotypic expression of different autosomal monosomies are still unknown. Recent studies of villous trophoblast hyperplasia have shown that trisomies 7, 15, 21 and 22 can be determinants of active proliferation of placental tissues. ${ }^{28,29}$ This is not surprising, as major growth factors (IGF2, HGF, EGF, PDGF-B) involved in the support of trophoblast proliferation have at least one ligand or receptor localized on chromosomes 7, 15 and $22 .^{29}$ Regarding chromosome 21 , there is a well-established increase in human chorionic gonadotropin titres and an enlarged volume of villous trophoblast in trisomy 21 pregnancies. $^{30}$ It is possible that the lethal effect of observed autosomal monosomies is caused by haploinsufficiency of certain gene(s) and controlled by dosagesensitive mechanisms.

Alternative mechanisms for the phenotype effects of mosaic monosomies connected with uniparental disomy (UPD) must be considered. UPD as a result of monosomy zygote rescue is a potential way of mosaic karyotype forming, especially for cases 3, 5 and 6 (see Table 2). It is important to note that, as imprinting loci on chromosomes 21 and 22 have not been discovered to date, nothing is known about the phenotype effects of UPD 21 or UPD 22 on early stages of human embryo development. The observation of two cases of maternal uniparental heterodisomy for chromosome 21 in spontaneous aborted embryos $^{31}$ indicates that further investigations are needed to check this assumption. Regarding chromosomes 7 and 15 , with well-established effects of genomic imprinting the

Table 4 Frequency of chromosomal abnormalities in first-trimester spontaneous abortion cells with low and normal proliferative capacity in vitro

\begin{tabular}{|c|c|c|c|c|c|c|c|}
\hline \multirow{2}{*}{ Study } & \multicolumn{3}{|c|}{ Low proliferative capacity } & \multicolumn{3}{|c|}{ Normal proliferative capacity } & \multirow{2}{*}{ P-value } \\
\hline & Methods & Cases & Abnormal karyotypes (\%) & Methods & Cases & Abnormal karyotypes (\%) & \\
\hline Daniely et al (1998) & $\mathrm{CGH}$ & 15 & 46.7 & Metaphase analysis & 12 & 41.7 & 0.80 \\
\hline Lomax et al (2000) & $\mathrm{CGH}$ & 32 & 62.5 & Metaphase analysis & 253 & 61.3 & 0.89 \\
\hline Fritz et al (2001) & $\mathrm{CGH}$ & 57 & 72.4 & Metaphase analysis & 4693 & 64.8 & 0.26 \\
\hline Total & $\mathrm{CGH}$ & 104 & 65.3 & Metaphase analysis & 4958 & 64.6 & 0.86 \\
\hline Present study & Interphase FISH & 60 & 53.3 & Metaphase analysis & 86 & 57.0 & 0.66 \\
\hline
\end{tabular}


mechanism of monosomy rescue is not appropriate for cases 1 and 2 due to a low level of abnormal cells confined to the cytotrophoblast. Apparently the probability of chromosome loss in a limited number of cells confined to the cytotrophoblast is higher than the duplication of a single chromosome copy both in cytotrophoblast and extraembryonic mesoderm. Moreover, if the last mechanism is realistic, then the cells with autosomal monosomy must be discovered in the extraembryonic mesoderm. We found no cells with monosomy 7 or 15 in this tissue, therefore the presence of UPD in these embryos is unlikely.

Other forms of chromosomal abnormalities in cells with low proliferative capacity were typical for spontaneous abortions (Table 3). Polyploid cells apparently have a normal proliferative activity. Moreover, we found the prevalence of mosaic polyploid cell lines in long-term cultures. Thus, the coincidence of overall numerical abnormalities rates in samples of spontaneous abortions with low and normal cell proliferation observed both in the present study and in the literature, is probably the result of differential effects of various forms of karyotype imbalance on cell phenotype.

The results of FISH analysis of uncultured cells from spontaneous abortions reveal a high frequency of both intra-tissue and confined placental mosaicism. This observation underlines the fact that early stages of human development are associated with a high rate of mitotic errors, ${ }^{7,32}$ and this is confirmed by data from molecular cytogenetic analyses of cleavage stage embryos. ${ }^{33}$ It is probable that mitotic instability is an important factor of early prenatal selection.

In conclusion, it is necessary to note that chromosomal abnormalities are not a unique factor influencing cell proliferation. It is possible that the gene content of different chromosomes, DNA polymorphism and epigenetic modifications have their own contribution to the cell proliferative capacity. Our results point out the significance of a careful molecular cytogenetic examination of cell culture failures for the elucidation of genetic background of prenatal selection in man.

\section{Acknowledgements}

We are grateful to Prof $M$ Rocchi (University of Bari, Italy) for the human centromere specific DNA probes. We thank Dr J D A Delhanty (UCL Centre for Preimplantation Genetic Diagnosis, Department of Obstetrics and Gynaecology, University College London, UK) for helpful comments on an early version of the manuscript. This work was supported by Russian Foundation for Basic Research (Grants Nos. 00-04-48092 and 01-04-06084).

\section{References}

1 Hassold TJ, Chen N, Funkhouser J et al.: A cytogenetic study of 1000 spontaneous abortions. Ann Hum Genet 1980; 44: 151-178.
2 Byrne J, Warburton D, Kline J, Blanc W, Stein Z: Morphology of early fetal death and their chromosomal characteristics. Teratology 1985; 32: 297-315.

3 Lin C, De Braekeleer M, Jamro H: Gytogenetic studies in spontaneous abortions: the Calgary experience. Can J Genet Cytol 1985; 27: 565-570.

4 Guerneri S, Bettio D, Simoni G, Brambati B, Lanzani A, Fraccaro M: Prevalence and distribution of chromosome abnormalities in a sample of first trimester internal abortions. Hum Reprod 1987; 2: $735-739$.

5 Dejmek J, Vojtassak J, Malova J: Cytogenetic analysis of 1508 spontaneous abortions originating from south Slovakia. Eur $J$ Obstet Gynecol Reprod Biol 1992; 46: 129-136.

6 Be CR, Velasquez PM, Youlton RR: A cytogenetic study in 609 abortions. Rev Med Chile 1997; 125: 317-322.

7 Griffin DK, Millie EA, Redline RW, Hassold TJ, Zaragoza MV: Cytogenetic analysis of spontaneous abortions: comparison of techniques and assessment of the incidence of confined placental mosaicism. Am J Med Genet 1997; 72: 297-301.

8 Griffin DK: The incidence, origin and etiology of aneuploidy. Int Rev Cytol 1996; 167: 263-296.

9 Hanna JS, Shires P, Matile G: Trisomy 1 in a clinically recognized pregnancy. Am J Med Genet 1997; 68: 98.

10 Rooney DE, Czepulkowski BH: Human Cytogenetics. A practical approach. New York: Oxford University Press; 1992.

11 Lomax BL, Kalousek DK, Kuchinka BD, Barrett IJ, Harrison KJ, Safavi $\mathrm{H}$ : The utilization of interphase cytogenetic analysis for the detection of mosaicism. Hum Genet 1994; 93: 243-247.

12 Cure S, Boue J, Boue A: Growth characteristics of human embryonic cell lines with chromosomal anomalies. Biomedicine 1974; 21: 233-236.

13 Grinberg KN, Terekhov SM: Chromosome imbalance and the cell proliferative potential in vitro. Bull Exp Biol Med 1985; 99: 191-193.

14 Qumsiyeh MB, Kim KR, Ahmed MN, Bradford W: Cytogenetics and mechanisms of spontaneous abortions: increased apoptosis and decreased cell proliferation in chromosomally abnormal villi. Cytogenet Cell Genet 2000; 88: 230-235.

15 Persutte WH, Lenke RR: Failure of amniotic-fluid cell growth: is it related to fetal aneuploidy? Lancet 1995; 345: 96-97.

16 Reid R, Sepulveda W, Kyle PM, Davies G: Amniotic fluid culture failure: clinical significance and association with aneuploidy. Obstet Gynecol 1996; 87: 588-592.

17 Lam YH, Tang MHY, Sin SY, Ghosh A: Clinical significance of amniotic fluid cell culture failure. Prenat. Diagn 1998; 18: 343-347.

18 Daniely M, Aviram-Goldring A, Barkai G, Aviram-Goldring A: Detection of chromosomal aberration in fetuses arising from recurrent spontaneous abortion by comparative genomic hybridization. Hum Reprod 1998; 13: 805-809.

19 Lomax BL, Tang S, Separovic E et al.: Comparative genomic hybridization in combination with flow cytometry improves results of cytogenetic analysis of spontaneous abortions. Am J Hum Genet 2000; 66: 1516-1521.

20 Fritz B, Hallermann C, Olert J et al.: Cytogenetic analysis of culture failures by comparative genomic hybridization (CGH)-re-evaluation of chromosome aberration rates in early spontaneous abortions. Eur J Hum Genet 2001; 9: 539-547.

21 Reddy KS: Double trisomy in spontaneous abortions. Hum Genet 1997; 101: 339-345.

22 Reddy KS: Triple aneuploidy in spontaneous abortions. Clin Genet 1999; 56: 103-104.

23 Benadiva CA, Kligman I, Munne S: Aneuploidy 16 in human embryos increases significantly with maternal age. Fertil Steril 1996; 66: 248-255.

24 Lebedev IN, Nazarenko SA: Tissue-specific placental mosaicism for autosomal trisomies in human spontaneous abortuses: mechanisms of formation and phenotypical effects. Russ J Genet 2001; 37: 1224-1237. 
25 Pellissier MC, Philip N, Voelckel-Baeteman MA, Mattei MG, Mattei JF: Monosomy 21: a new case confirmed by in situ hybridization. Hum Genet 1987; 75: 95-96.

26 Garzicic B, Guc-Scekic M, Pilic-Radivojevic G, Ignjatovic M, Vilhar N: A case of monosomy 21. Ann Genet 1988; 31: 247-249.

27 Ginsburg C, Fokstuen S, Schinzel A: The contribution of uniparental disomy to congenital development defects in children born to mothers at advanced childbearing age. Am J Med Genet 2000; 95: 454-460.

28 Redline RW, Hassold T, Zaragoza M: Determinants of villous trophoblastic hyperplasia in spontaneous abortions. Mod Pathol 1998; 11: 762-768.

29 Zaragoza MV, Millie E, Redline RW, Hassold TJ: Studies of nondisjunction in trisomies 2, 7, 15 and 22: does the parental origin of trisomy influence placental morphology? J Med Genet 1998; 35: 924-931.
30 Bogart $\mathrm{MH}$, Pandian MR, Jones OW: Abnormal maternal serum chorionic gonadotropin levels in pregnancies with fetal chromosomal abnormalities. Prenat Diagn 1987; 7: $623-630$.

31 Henderson DJ, Sherman LS, Loughna SC, Bennett PR, Moore GE: Early embryonic failure associated with uniparental disomy for human chromosome 21. Hum Mol Genet 1994; 3: $1373-1376$

32 Hendricks SK, Pratt L, Cardwell M, Prentice E, Wu SQ: The increased efficacy of FISH and placental touch preparation in the diagnosis of confined placental mosaicism (CPM). Am J Hum Genet 1995; 57 (Suppl): A280.

33 Harper JC, Coonen E, Handyside AH, Wintson RM, Hopman AH, Delhanty JD: Mosaicism of autosomes and sex chromosomes in morphologically normal, monospermic preimplantation embryos. Prenat Diagn 1995; 15: 41-49. 